\title{
Vitamin D Status, Disease Activity, and Endothelial Dysfunction in Early Rheumatoid Arthritis Patients
}

\author{
Alexandru Caraba, ${ }^{1}$ Viorica Crişan, ${ }^{2}$ Ioan Romoşan, ${ }^{3}$ Ioana Mozoș, ${ }^{4}$ and Marius Murariu ${ }^{5}$ \\ ${ }^{1}$ Department of Internal Medicine, Division of Rheumatology, University of Medicine and Pharmacy "Victor Babeş", \\ Timişoara, Romania \\ ${ }^{2}$ Division of Rheumatology, Timişoara, Romania \\ ${ }^{3}$ Department of Internal Medicine, University of Medicine and Pharmacy "Victor Babeş", Timişoara, Romania \\ ${ }^{4}$ Department of Pathophysiology, University of Medicine and Pharmacy "Victor Babeş", Timişoara, Romania \\ ${ }^{5}$ University of Medicine and Pharmacy "Victor Babeş", Timişoara, Romania
}

Correspondence should be addressed to Alexandru Caraba; alexcaraba@yahoo.com

Received 29 June 2017; Revised 16 September 2017; Accepted 28 September 2017; Published 22 October 2017

Academic Editor: Zhongjie Shi

Copyright (c) 2017 Alexandru Caraba et al. This is an open access article distributed under the Creative Commons Attribution License, which permits unrestricted use, distribution, and reproduction in any medium, provided the original work is properly cited.

Cardiovascular diseases represent important complications in rheumatoid arthritis (RA) patients, generated by an accelerated atherosclerosis. The aim of this study is represented by the assessment of the correlations between serum levels of vitamin D, disease activity, and endothelial dysfunction in patients with early RA. Material and Methods. The study was performed on a group of 35 patients with early RA and 35 healthy subjects matched for age and gender, as controls. In all studied subjects, the following were determined: inflammatory markers, insulin resistance, vitamin D levels, and endothelial dysfunction. Statistical analysis were performed using the Student's $t$-test and the Pearson's test. $p$ values of less than 0.05 were considered statistically significant. Results. The group of patients with RA patients presented inflammation, low levels of vitamin D, elevated insulin resistance, and reduced flow-mediated vasodilation, statistically significant compared to the control group $(p<0.00001)$. Significant inverse correlations between the levels of $25(\mathrm{OH})$ vitamin D and DAS28, respective insulin resistance, and significant positive correlation between $25(\mathrm{OH})$ vitamin $\mathrm{D}$ and endothelial function were demonstrated. Conclusion. In early RA patients with moderate and high disease activity, low serum levels of vitamin $\mathrm{D}$ were associated with disease activity, increased insulin resistance, and endothelial dysfunction.

\section{Introduction}

Rheumatoid arthritis (RA) is a chronic inflammatory autoimmune disorder, which typically involves smalland medium-sized joints. Rheumatoid synovitis generates cartilage breakdown, bony erosions, and loss of function of the involved joints [1]. But besides articular involvement, cardiovascular disease generated by accelerated, premature atherosclerosis represents a serious complication of RA. It is known that in RA patients, cardiovascular disease represents the cause of $40-50 \%$ of the deaths in this group of population [2,3]. Atherosclerosis is a complex process, which develops over the course of many years, beginning in the early teenage years, and endothelial dysfunction represents the first step in its development $[4,5]$.

Lin et al. showed in their meta-analysis that the RA patients exhibit lower vitamin $\mathrm{D}$ levels than healthy controls, and, on the other hand, these levels present an inverse correlation with the disease activity [6]. Other studies demonstrated the role of vitamin D in RA activity [7-10]. Besides the role in bone mineral metabolism, vitamin $\mathrm{D}$ has anti-inflammatory and immunomodulatory roles. By antiproliferative, antiangiogenic, and antioxidant properties, vitamin $\mathrm{D}$ offers protective effects on the cardiovascular system $[11,12]$. 
TABLE 1: Demographic data in RA patients and controls.

\begin{tabular}{lcc}
\hline Parameter & $\begin{array}{c}\text { Value (mean } \pm \text { standard deviation) } \\
\text { RA patients }\end{array}$ & 35 \\
\hline Sex $[n(\%)]$ & 35 & $12(34.28 \%)$ \\
$\quad$ Males & $12(34.28 \%)$ & $23(65.72 \%)$ \\
Females & $23(65.72 \%)$ & $54.14 \pm 6.28$ \\
Mean age (years) & $55.6 \pm 9.74$ & - \\
Mean length of RA evolution (months) & $14.25 \pm 5.27$ & - \\
The drugs used by the RA patients in & Methotrexate (30 patients; $13.28 \pm 2.25 \mathrm{mg} /$ week $)$ \\
the moment of investigation & and leflunomide (5 patients; $20 \mathrm{mg} /$ day) \\
\hline
\end{tabular}

The aim of this study is represented by the assessment of the associations between serum levels of vitamin $\mathrm{D}$, disease activity, and endothelial dysfunction in patients with early rheumatoid arthritis.

\section{Material and Methods}

2.1. Patients. The study was performed on a group of 35 patients with early RA and 35 healthy subjects matched for age and gender, as controls. The diagnosis of RA was established based on the 2010 American College of Rheumatology/European League Against Rheumatism Classification Criteria for Rheumatoid Arthritis [13]. All patients had a disease duration of less than 2 years. Exclusion criteria were as follows: previous steroid therapy or drugs that alter insulin sensitivity, diabetes mellitus, uncontrolled arterial hypertension, dyslipidemia, chronic kidney disease, thyroid dysfunction, Cushing's syndrome, current smokers, patients with history of acute coronary syndrome during the last 6 months, pregnancy, and patients taking vitamin $\mathrm{D}$ replacement therapy. All patients gave their informed consent. The study was approved by the Ethics Committee of University of Medicine and Pharmacy "Victor Babeş" Timişoara, Romania.

2.2. Methods. In all patients, the following were determined: anti-citrullinated peptide antibodies (chemiluminescent microparticle immunoassay, serum), rheumatoid factor (turbidimetry, serum), erythrocyte sedimentation rate (ESR) (Electro Optical System Technologies), C-reactive protein (turbidimetry, serum), fibrinogen (coagulation, plasma citrate), TNF- $\alpha$ (chemiluminescence immunoassay, serum), IL-6 (electrochemiluminescence immunoassay, serum), fasting insulinemia (chemiluminescence immunoassay, serum) and glycemia (photometry, plasma NaF K2 oxalate), and vitamin D levels $(25(\mathrm{OH})$ vitamin D) (chemiluminescence immunoassay, serum)

Rheumatoid arthritis activity was assessed using Disease Activity Score 28 (DAS28). DAS28 was calculated based on ESR, tender joint count (28 joints), swollen joint count (28 joints), and the patient's assessment of global well-being (100 mm visual analogue scale) (http://www.4s-dawn.com/ DAS28/DAS28.html).
Insulin resistance was assessed by homeostasis model assessment of insulin resistance (HOMA-IR) index, using fasting insulin and glucose [14].

Endothelial dysfunction was assessed by means of flowmediated vasodilation, on brachial artery, using B-mode ultrasonography (Siemens Acuson X300 Ultrasound System, with linear transducer of $10 \mathrm{MHz}$ ). Before the test, the patient was relaxed at a stable room temperature between $20-25^{\circ} \mathrm{C}$; ingestion of caffeine, high-fat foods, and vitamin $\mathrm{C}$ was prohibited. The diameter of the brachial artery was measured incidentally with the $R$ wave of the electrocardiograph trace $(\mathrm{Di})$. Then, ischemia was induced by inflating the pneumatic cuff to a pressure $50 \mathrm{mmHg}$ above systolic one, in order to obliterate the brachial artery and induce ischaemia. After 5 minutes, the cuff was deflated and the diameter was measured after 60-second postdeflation (Df). FMD was calculated with the formula: $\mathrm{FMD}=[(\mathrm{Df}-\mathrm{Di}) / \mathrm{Di}] \times 100[15]$.

In controls, the following were determined: erythrocyte sedimentation rate (ESR), C-reactive protein, fibrinogen, TNF- $\alpha$, IL-6, fasting insulinemia and glycemia, vitamin D levels, insulin resistance, and flow-mediated vasodilation, using the same methods.

2.3. Statistical Analysis. Data were expressed as mean \pm standard deviation. Statistical analyses were performed using the Student's $t$-test and Pearson's correlation. Differences were considered statistically significant at the value of $p<0.05$.

\section{Results}

The demographic data of patients and controls are presented in Table 1.

All patients were positive for rheumatoid factor and anticitrullinated peptide antibodies.

The laboratory findings of RA patients and controls are presented in Table 2.

By analyzing these data, it can be observed that all RA patients presented inflammation, low levels of vitamin $\mathrm{D}$, elevated insulin resistance, and reduced flow-mediated vasodilation. These parameters showed statistically significant differences between RA patients and controls, as presented in Table 2. 
TABLE 2: Laboratory findings in RA patients and controls.

\begin{tabular}{|c|c|c|c|}
\hline \multirow{2}{*}{ Parameter } & \multicolumn{2}{|c|}{ Value (mean \pm standard deviation) } & \multirow[b]{2}{*}{$p$} \\
\hline & RA patients & Controls & \\
\hline $\operatorname{ESR}(\mathrm{mm} / \mathrm{h})$ & $74.11 \pm 18.47$ & $8.45 \pm 2.99$ & $<0.00001$ \\
\hline C-reactive protein $(\mathrm{mg} / \mathrm{l})$ & $60.34 \pm 27.8$ & $2.88 \pm 0.98$ & $<0.00001$ \\
\hline Fibrinogen $(\mathrm{mg} / \mathrm{dl})$ & $693.52 \pm 284.61$ & $207.18 \pm 95.24$ & $<0.0001$ \\
\hline DAS28 & $6.41 \pm 0.94$ & - & - \\
\hline TNF- $\alpha(\mathrm{pg} / \mathrm{ml})$ & $89.65 \pm 21.41$ & $3.76 \pm 1.64$ & $<0.00001$ \\
\hline IL-6 (pg/ml) & $90.15 \pm 20.79$ & $4.41 \pm 1.78$ & $<0.00001$ \\
\hline FMD (\%) & $7.94 \pm 0.81$ & $13.78 \pm 1.43$ & $<0.00001$ \\
\hline HOMA-IR & $5.97 \pm 1.89$ & $1.23 \pm 0.19$ & $<0.00001$ \\
\hline $25(\mathrm{OH})$ vitamin $\mathrm{D}$ & $14.90 \pm 2.81$ & $36.39 \pm 7.78$ & $<0.00001$ \\
\hline
\end{tabular}

TABle 3: Differences of FMD, HOMA-IR, and 25(OH) vitamin D between moderate and high disease activity RA patients.

\begin{tabular}{|c|c|c|c|}
\hline \multirow{2}{*}{ Parameter } & \multicolumn{2}{|c|}{ Disease activity } & \multirow[b]{2}{*}{$p$} \\
\hline & Moderate & High & \\
\hline Number of patients & 4 & 31 & \\
\hline DAS28 & $4.63 \pm 0.26$ & $6.64 \pm 0.73$ & $<0.0001$ \\
\hline FMD (\%) & $8.88 \pm 0.88$ & $7.23 \pm 0.82$ & $<0.05$ \\
\hline HOMA-IR & $4.27 \pm 1.23$ & $6.13 \pm 1.92$ & $<0.05$ \\
\hline $25(\mathrm{OH})$ vitamin $\mathrm{D}$ & $19.15 \pm 0.72$ & $14.35 \pm 2.49$ & $<0.0001$ \\
\hline
\end{tabular}

Among the RA patients, only one had vitamin D insufficiency, while another 34 patients had vitamin D deficiency.

Based on DAS28 value, the RA patients were divided into two subgroups: one with moderate disease activity and the other with high disease activity. The RA patients with high disease activity presented lower values of FMD and $25(\mathrm{OH})$ vitamin D and higher values of HOMA-IR, compared with the RA patients with moderate disease activity (Table 3 ).

The results of this study showed that the entire group of patients with early active RA presented low levels of $25(\mathrm{OH})$ vitamin $\mathrm{D}$, high insulin resistance, and endothelial dysfunction.

There were demonstrated significant inverse correlations between the levels of $25(\mathrm{OH})$ vitamin $\mathrm{D}$ and DAS28 $(p=0.0011)$, and respective insulin resistance $(p=0.0389)$, and significant positive correlation between $25(\mathrm{OH})$ vitamin $\mathrm{D}$ and endothelial function, expressed as $\operatorname{FMD}(p=0.0010)$. The same correlations were identified in the two subgroups of patients with moderate disease activity and respective high disease activity (Table 4, Figures 1, 2, and 3).

Studying the correlations between proinflammatory cytokines and the levels of $25(\mathrm{OH})$ vitamin $\mathrm{D}$, significant inverse correlations were identified between $25(\mathrm{OH})$ vitamin $\mathrm{D}$ and TNF- $\alpha(r=-0.4269, p=0.0105)$, respective IL-6 $(r=-0.3627, p=0.0322)$.

On the other hand, high disease activity of RA, expressed as DAS28, has been positively correlated with insulin resistance $(r=0.3692, p=0.0029)$ and negatively correlated with FMD $(r=-0.3912, p=0.0020)$.

\section{Discussion}

Rheumatoid arthritis affects up to $1 \%$ of adults worldwide, representing a serious public health problem, because of articular and extra-articular involvement. Morbidity and mortality due to atherosclerotic cardiovascular diseases are increased in RA patients $[16,17]$. Based on the studies of Meune et al. and Avina-Zubieta et al., RA is associated with a 1.48-fold increase in atherosclerotic cardiovascular diseases and a 1.6-fold increase in cardiovascular diseaserelated death, compared to the general population $[18,19]$. Atherosclerotic cardiovascular disease in RA patients has more severe presentation and worse outcomes compared to the general population [20]. Traditional cardiovascular risk factors and RA-related risk factors contribute to this excess of cardiovascular morbidity and mortality of these patients. Among RA-related risk factors, proinflammatory cytokines (TNF- $\alpha$, IL-6), oxidative stress, an increase of leptin and resistin (proatherogenic hormones) and the decrease of adiponectin (antiatherogenic hormone), and insulin resistance play the most important role in accelerated atherogenesis. The first step in the atherosclerosis process is represented by the endothelial dysfunction $[4,19,21]$.

In the last couple of years, it has been emphasized the role of vitamin D in health and disease. Besides the well-known effects on bone metabolism, vitamin $\mathrm{D}$ has effects on the immune and cardiovascular systems [22-24].

Normal levels of vitamin $\mathrm{D}$ are required to maintain the physiological innate and adaptive immune responses and the immune tolerance of self-antigens. Vitamin D deficiency is associated with the loss of immune tolerance and the appearance of autoimmunity processes, including rheumatoid arthritis [16, 22, 25-27]. The protective effects of vitamin $\mathrm{D}$ on the cardiovascular system are represented by the increase of anti-inflammatory cytokine expression (such as IL-10) and by the decrease of proinflammatory molecule expression (such as TNF- $\alpha$ and IL-6) [28].

The connections between low levels of vitamin $\mathrm{D}$, inflammation, insulin resistance, and endothelial dysfunction in rheumatoid arthritis are very complex.

Accelerated atherosclerosis associated with RA is related to systemic inflammation, which characterized this disease [29]. Systemic inflammation contributes to the initiation 
TABLE 4: Correlations between $25(\mathrm{OH})$ vitamin D and disease activity, insulin resistance, and endothelial function in RA patients.

\begin{tabular}{lccc}
\hline Correlation & Whole group & Moderate disease activity group & High disease activity group \\
\hline \multirow{2}{*}{$25(\mathrm{OH})$ vitamin D-DAS28 } & $r=-0.5253$ & $r=-0.9072$ & $r=-0.3198$ \\
& $p=0.0011$ & $p=0.046$ & $p=0.0397$ \\
$25(\mathrm{OH})$ vitamin D-HOMA-IR & $r=-0.3506$ & $r=-0.9813$ & $r=-0.3200$ \\
& $p=0.0389$ & $p=0.009$ & $p=0.0396$ \\
$25(\mathrm{OH})$ vitamin D-FMD & $r=0.5287$ & $r=0.9001$ & $p=0.5144$ \\
& $p=0.0010$ & $p=0.049$ & $p=0.001$ \\
\hline
\end{tabular}

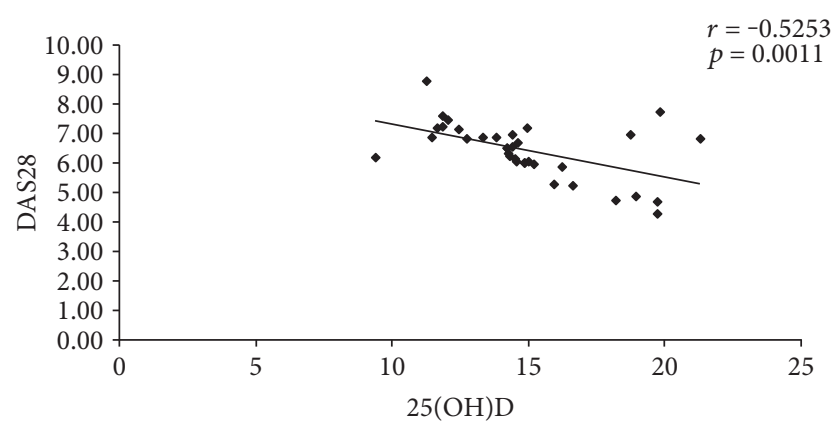

Figure 1: Correlation between 25(OH)D and DAS28.

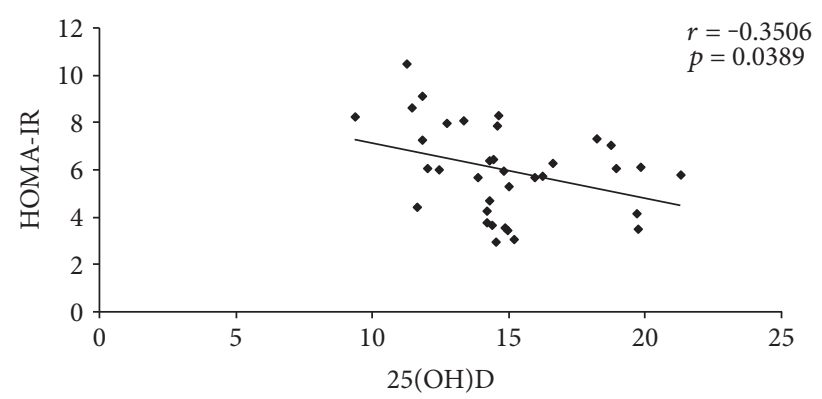

Figure 2: Correlation between 25(OH)D and HOMA-IR.

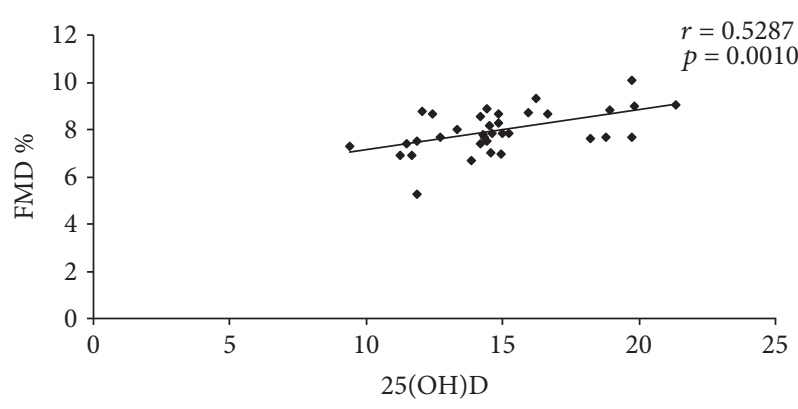

FIGURE 3: Correlation between 25(OH)D and FMD\%.

and development of accelerated atherosclerosis, since inflammatory processes in the rheumatoid synovium and atherosclerotic plaques are remarkably similar. Inflammatory response acts in endothelial dysfunction appearance by means of proinflammatory cytokines, such as TNF- $\alpha$, IL- 6 , and IL-1 [30]. In RA, low levels of vitamin D are noted to be common and are even more prevalent than in the general population. These low levels are described to be associated with some cardiovascular risk factors $[2,12,31]$. But vitamin $\mathrm{D}$ deficiency is associated with an exacerbation of Th1 immune response, resulting in the upregulation of the expression and production of several proinflammatory cytokines including TNF- $\alpha$, IL- $1 \beta$, IL- 6 , and IL- 8 , too [32-34]. Inflammatory responses play a crucial role in the pathogenesis and development of IR [35], and the low levels of 25(OH) vitamin D are associated with IR [36]. Insulin resistance induces vasoconstriction and vascular smooth muscle cell proliferation, generating endothelial dysfunction [37].

In the present study, the levels of $25(\mathrm{OH})$ vitamin D were decreased in all studied patients, compared with controls $(p<0.00001)$, as it has been shown in other studies $[2,12,31]$. Significant inverse correlations $(p=0.0105$ for TNF- $\alpha$, respective $p=0.0322$ for IL- 6 ) have been highlighted between the levels of proinflammatory cytokines (TNF- $\alpha$ and IL-6) and the levels of $25(\mathrm{OH})$ vitamin $\mathrm{D}$. Welsh et al. showed that the degree of systemic inflammation is inversely associated with the circulating levels of vitamin D [31].

Vitamin D may also have a role in modulating RA disease activity [7]. The results of the present study showed that the low levels of $25(\mathrm{OH})$ vitamin $\mathrm{D}$ were correlated in an inversely manner with the RA activity, expressed as DAS28 $(p=0.0011)$. The same inverse correlations were identified in RA patients with moderate disease activity $(p=0.046)$ and respective high disease activity $(p=0.0397)$. Rossini et al., studying 1191 RA patients and 1019 healthy controls, identified a significant inverse correlation between the logarithm of the $25(\mathrm{OH})$ vitamin D levels and the RA activity $(p=0.002)$ [38]. Hong et al. demonstrated on the 130 patients with RA and 80 healthy controls that the RA patients had lower levels of 25(OH) vitamin D and these levels correlated significantly with the RA activity $(r=-0.43)$ [16]. El-Barbary et al. included in their study forty early RA patients and forty healthy controls. The authors demonstrated the significant negative correlation between $25(\mathrm{OH})$ vitamin D levels and DAS28, respective IL-6 $(p<0.001)$ [39]. Other studies obtained the same relationship between the levels of serum $25(\mathrm{OH})$ vitamin $\mathrm{D}$ and disease activity in RA patients, reporting the correlation 
coefficient as $r=-0.57$ [40], $r=-0.431$ [41], $r=-0.42$ [42], and $r=-0.604$ [43].

Hypovitaminosis D increases the insulin resistance and may trigger endothelial dysfunction [44]. In our study, it was identified a significant inverse correlation between low levels of serum $25(\mathrm{OH})$ vitamin $\mathrm{D}$ and insulin resistance, expressed as HOMA-IR $(p=0.0389)$. Strong inverse correlation was obtained in both subgroups of rheumatoid patients with moderate disease activity $(p=0.009)$ and respective high disease activity $(p=0.0396)$. Hirschler et al. reported the same results in their study $(r=-0.29, p=0.002)$ [45]. The role of vitamin $\mathrm{D}$ in modulating insulin sensitivity is emphasized in the study published by Miñambres et al. [46].

Previous studies have shown that insulin resistance is associated with endothelial dysfunction, an early marker of atherosclerosis [21, 47, 48].

Borges et al. demonstrated that vitamin $\mathrm{D}$ improved the endothelial function, suggesting the relationship between hypovitaminosis D and endothelial dysfunction [49]. The present study showed the positive correlation between the serum levels of $25(\mathrm{OH})$ vitamin $\mathrm{D}$ and endothelial function expressed as FMD $(p=0.0010)$. In the subgroup of RA patients with moderate disease activity, it was shown a positive correlation between the serum levels of $25(\mathrm{OH})$ vitamin $\mathrm{D}$ and endothelial function $(p=0.049)$, while in a subgroup of patients with high disease activity, the correlation was positive, too, but more significant $(p=0.001)$. The explanation of this finding is based on the fact that high disease activity is associated with lower levels of $25(\mathrm{OH})$ vitamin $\mathrm{D}$, higher inflammatory responses and insulin resistance, and significant endothelial dysfunction [35-37]. In their study, Jablonski et al. found endothelial dysfunction in adults with hypovitaminosis D, as opposed to patients with normal levels of this vitamin [50]. In RA patients with vitamin D deficiency, Ranganathan et al. revealed a significant correlation between serum $25(\mathrm{OH})$ vitamin $\mathrm{D}$ and endothelial function $(p=0.04)[51]$.

Our study revealed that low levels of $25(\mathrm{OH})$ vitamin $\mathrm{D}$ were associated with high disease activity, high insulin resistance, and endothelial dysfunction in early RA patients. But disease activity in itself contributes to the development of atherosclerosis through insulin resistance [52-54]. Between DAS28, as a marker of RA activity and FMD, it was observed as an inverse correlation $(r=-0.3912, p=0.020)$, and, on the other hand, between DAS28 and insulin resistance it was identified as a positive significant correlation $(r=0.3692, p=0.029)$.

The present study had some limitations. The first limitation was the small sample size, being investigated only 35 patients. Second, only the serum $25(\mathrm{OH}) \mathrm{D}$ was determined. The free bioavailable vitamin $\mathrm{D}$ and vitamin $\mathrm{D}$-binding protein were not measured.

\section{Conclusion}

In early RA patients with moderate and high disease activity, low serum levels of vitamin D were associated with disease activity, increased insulin resistance, and endothelial dysfunction.

\section{Conflicts of Interest}

The authors declare no conflicts of interest.

\section{References}

[1] V. Majithia and S. A. Geraci, "Rheumatoid arthritis: diagnosis and management," The American Journal of Medicine, vol. 120, no. 11, pp. 936-939, 2007.

[2] A. Lo Gullo, G. Mandraffino, G. Bagnato et al., "Vitamin D status in rheumatoid arthritis: inflammation, arterial stiffness and circulating progenitor cell number," PLoS One, vol. 10, no. 8, article e0134602, 2015.

[3] C. Tanasescu, C. Jurcut, R. Jurcut, and C. Ginghina, "Vascular disease in rheumatoid arthritis: from subclinical lesions to cardiovascular risk," European Journal of Internal Medicine, vol. 20, no. 4, pp. 348-354, 2009.

[4] M. J. Peters, D. P. Symmons, D. McCarey et al., "EULAR evidence-based recommendations for cardiovascular risk management in patients with rheumatoid arthritis and other forms of inflammatory arthritis," Annals of the Rheumatic Diseases, vol. 69, no. 2, pp. 325-331, 2010.

[5] W. Insull Jr, "The pathology of atherosclerosis: plaque development and plaque responses to medical treatment," The American Journal of Medicine, vol. 122, Supplement 1, pp. S3-S14, 2009.

[6] J. Lin, J. Liu, M. L. Davies, and W. Chen, "Serum vitamin D level and rheumatoid arthritis disease activity: review and meta-analysis," PLoS One, vol. 11, no. 1, article e0146351, 2016.

[7] P. Leventis and S. Patel, "Clinical aspects of vitamin D in the management of rheumatoid arthritis," Rheumatology, vol. 47, no. 11, pp. 1617-1621, 2008.

[8] Y. Braun-Moscovici, K. Toledano, D. Markovits, A. Rozin, A. M. Nahir, and A. Balbir-Gurman, "Vitamin D level: is it related to disease activity in inflammatory joint disease?," Rheumatology International, vol. 31, no. 4, pp. 493-499, 2011.

[9] P. Gatenby, R. Lucas, and A. Swaminathan, "Vitamin D deficiency and risk for rheumatic diseases," Current Opinion in Rheumatology, vol. 25, no. 2, pp. 184-191, 2013.

[10] A. Dehghan, S. Rahimpour, H. Soleymani-Salehabadi, and M. B. Owlia, "Role of vitamin D in flare-ups of rheumatoid arthritis," Zeitschrift für Rheumatologie, vol. 73, no. 5, pp. 461-464, 2014.

[11] A. Neve, A. Corrado, and F. P. Cantatore, "Immunomodulatory effects of vitamin D in peripheral blood monocyte-derived macrophages from patients with rheumatoid arthritis," Clinical and Experimental Medicine, vol. 14, no. 3, pp. 275-283, 2014.

[12] A. Urruticoechea-Arana, M. A. Martin-Martinez, S. Castaneda et al., "Vitamin D deficiency in chronic inflammatory rheumatic diseases: results of the cardiovascular in rheumatology [CARMA] study," Arthritis Research \& Therapy, vol. 17, no. 1, p. 211, 2015.

[13] D. Aletaha, T. Neogi, A. J. Silman et al., "2010 Rheumatoid arthritis classification criteria: an American College of Rheumatology/European League Against Rheumatism collaborative initiative," Arthritis \& Rheumatism, vol. 62, no. 9, pp. 2569-2581, 2010.

[14] B. Antuna-Puente, E. Disse, R. Rabasa-Lhoret, M. Laville, J. Capeau, and J.-P. Bastard, "How can we measure insulin sensitivity/resistance?," Diabetes \& Metabolism, vol. 37, no. 3, pp. 179-188, 2011. 
[15] M. C. Corretti, T. J. Anderson, E. J. Benjamin et al., "Guidelines for the ultrasound assessment of endothelial-dependent flowmediated vasodilation of the brachial artery: a report of the International Brachial Artery Reactivity Task Force," Journal of the American College of Cardiology, vol. 39, no. 2, pp. 257$265,2002$.

[16] Q. Hong, J. Xu, S. Xu, L. Lian, M. Zhang, and C. Ding, "Associations between serum 25-hydroxyvitamin D and disease activity, inflammatory cytokines and bone loss in patients with rheumatoid arthritis," Rheumatology, vol. 53, no. 11, pp. 1-8, 2014.

[17] S. Skeoch and I. Bruce, "Atherosclerosis in rheumatoid arthritis: is it all about inflammation?," Nature Review Rheumatology, vol. 11, no. 7, pp. 390-400, 2015.

[18] C. Meune, E. Touzé, L. Trinquart, and Y. Allanore, "Trends in cardiovascular mortality in patients with rheumatoid arthritis over 50 years: a systematic review and metaanalysis of cohort studies," Rheumatology, vol. 48, no. 10, pp. 1309-1313, 2009.

[19] J. A. Avina-Zubieta, J. Thomas, M. Sadatsafavi, A. J. Lehman, and D. Lacaille, "Risk of incident cardiovascular events in patients with rheumatoid arthritis: a meta-analysis of observational studies," Annals of the Rheumatic Diseases, vol. 71, no. 9, pp. 1524-1529, 2012.

[20] A. Mantel, M. Holmqvist, T. Jernberg, S. Wållberg-Jonsson, and J. Askling, "Rheumatoid arthritis is associated with a more severe presentation of acute coronary syndrome and worse short-term outcome," European Heart Journal, vol. 36, no. 48, pp. 3413-3422, 2015.

[21] N. Sattar, D. W. McCarey, H. Capell, and I. B. McInnes, "Explaining how 'high-grade' systemic inflammation accelerates vascular risk in rheumatoid arthritis," Circulation, vol. 108, no. 24, pp. 2957-2963, 2003.

[22] H. F. Deluca and M. T. Cantorna, "Vitamin D: its role and uses in immunology," FASEB Journal, vol. 15, no. 14, pp. 25792585, 2001.

[23] M. L. Melamed, E. D. Michos, W. Post, and B. Astor, "25-Hydroxyvitamin D levels and the risk of mortality in the general population," Archives of Internal Medicine, vol. 168, no. 15, pp. 1629-1637, 2008.

[24] D. H. Kim, S. Sabour, U. N. Sagar, S. Adams, and D. J. Whellan, "Prevalence of hypovitaminosis D in cardiovascular diseases (from the National Health and Nutrition Examination Survey 2001 to 2004)," The American Journal of Cardiology, vol. 102, no. 11, pp. 1540-1544, 2008.

[25] N. Maruotti and F. P. Cantatore, "Vitamin D and the immune system," The Journal of Rheumatology, vol. 37, no. 3, pp. 491495, 2010.

[26] M. Hewison, "An update on vitamin D and human immunity," Clinical Endocrinology, vol. 76, no. 3, pp. 315-325, 2012.

[27] T. Lequerre and C. Richez, "Pathophysiology of rheumatoid arthritis," La Revue du Praticien, vol. 62, no. 8, pp. 10851093, 2012.

[28] A. Zittermann, S. S. Schleithoff, and R. Koerfer, "Putting cardiovascular disease and vitamin $\mathrm{D}$ insufficiency into perspective," The British Journal of Nutrition, vol. 94, no. 4, pp. 483-492, 2005.

[29] A. Lo Gullo, G. Mandraffino, M. A. Sardo et al., "Circulating progenitor cells in rheumatoid arthritis: association with inflammation and oxidative stress," Scandinavian Journal of Rheumatology, vol. 43, no. 3, pp. 184-193, 2014.
[30] T. Zegkos, G. Kitas, and T. Dimitroulas, "Cardiovascular risk in rheumatoid arthritis: assessment, management and next steps," Therapeutic Advances in Musculoskeletal Disease, vol. 8, no. 3, pp. 86-101, 2016.

[31] P. Welsh, M. J. Peters, and N. Sattar, "Is vitamin D in rheumatoid arthritis a magic bullet or a mirage? The need to improve the evidence base prior to calls for supplementation," Arthritis \& Rheumatism, vol. 63, no. 7, pp. 17631769, 2011.

[32] C. D. L. Marques, A. T. Dantas, T. S. Fragoso, and A. L. Duarte, "The importance of vitamin D levels in autoimmune diseases," Revista Brasileira de Reumatologia, vol. 50, no. 1, pp. 67-80, 2010.

[33] E. K. Calton, K. N. Keane, P. Newsholme, and M. J. Soares, "The impact of vitamin D levels on inflammatory status: a systematic review of immune cell studies," PLoS One, vol. 10, no. 11, article e0141770, 2015.

[34] J. J. Cannell, W. B. Grant, and M. F. Holick, "Vitamin D and inflammation," Dermato-Endocrinology, vol. 6, no. 1, article e983401, 2014.

[35] K. Rehman and M. Sajid Hamid Akash, "Mechanisms of inflammatory responses and development of insulin resistance: how are they interlinked?," Journal of Biomedical Science, vol. 23, no. 1, p. 87, 2016.

[36] U. J. Haque, J. M. Bathon, and J. T. Giles, “Association of vitamin D with cardiometabolic risk factors in rheumatoid arthritis," Arthritis Care \& Research, vol. 64, no. 10, pp. 1497-1504, 2012.

[37] A. Janus, E. Szahidewicz-Krupska, G. Mazur, and A. Doroszko, "Insulin resistance and endothelial dysfunction constitute a common therapeutic target in cardiometabolic disorders," Mediators of Inflammation, vol. 2016, Article ID 3634948, 10 pages, 2016.

[38] M. Rossini, S. Maddali Bongi, G. La Montagna et al., "Vitamin $\mathrm{D}$ deficiency in rheumatoid arthritis: prevalence, determinants and associations with disease activity and disability," Arthritis Research \& Therapy, vol. 12, no. 6, p. R216, 2010.

[39] A. M. El-Barbary, M. S. Hussein, E. M. Rageh, S. A. Essa, and H. A. Zaytoun, "Vitamin D receptor gene polymorphism in rheumatoid arthritis and its association with atherosclerosis," Egyptian Rheumatology Rehabilitation, vol. 42, pp. 145-152, 2015.

[40] M. Cutolo, K. Otsa, K. Laas et al., "Circannual vitamin D serum levels and disease activity in rheumatoid arthritis: Northern versus Southern Europe," Clinical and Experimental Rheumatology, vol. 24, no. 6, pp. 702-704, 2006.

[41] A. D. Turhanoglu, H. Guler, Z. Yonden, F. Aslan, A. Mansuroglu, and C. Ozer, "The relationship between vitamin $\mathrm{D}$ and disease activity and functional health status in rheumatoid arthritis," Rheumatology International, vol. 31, no. 7, pp. 911-914, 2011.

[42] S. M. Attar, "Vitamin D deficiency in rheumatoid arthritis. Prevalence and association with disease activity in Western Saudi Arabia," Saudi Medical Journal, vol. 33, no. 5, pp. 520525, 2012.

[43] R. Sharma, R. Saigal, L. Goyal et al., "Estimation of vitamin D levels in rheumatoid arthritis patients and its correlation with the disease activity," The Journal of the Association of Physicians of India, vol. 62, no. 8, pp. 678-681, 2014.

[44] O. Tarcin, O. G. Yavuz, B. Ozben et al., "Effect of vitamin D deficiency and replacement on endothelial function in 
asymptomatic subjects," The Journal of Clinical Endocrinology and Metabolism, vol. 94, no. 10, pp. 4023-4030, 2009.

[45] V. Hirschler, G. Maccallinni, T. Gilligan et al., "Association of vitamin $\mathrm{D}$ with insulin resistance in Argentine boys: a pilot study," Journal Pediatric Biochemistry, vol. 2, no. 2, pp. 091099, 2016.

[46] I. Miñambres, J. L. Sanchez-Quesada, and A. Pérez, “The association between hypovitaminosis D and metabolic syndrome: current understanding," Clinical Lipidology, vol. 10, no. 6, pp. 513-524, 2015.

[47] P. T. McSorley, P. M. Bell, I. S. Young et al., "Endothelial function, insulin action and cardiovascular risk factors in young healthy adult offspring of parents with type 2 diabetes: effect of vitamin $\mathrm{E}$ in a randomized double-blind, controlled clinical trial," Diabetic Medicine, vol. 22, no. 6, pp. 703-710, 2005.

[48] I. Ferraz-Amaro, C. González-Juanatey, R. López-Mejias, L. Riancho-Zarrabeitia, and M. A. González-Gay, "Metabolic syndrome in rheumatoid arthritis," Mediators of Inflammation, vol. 2013, Article ID 710928, 11 pages, 2013.

[49] A. C. Borges, T. Feres, L. M. Vianna, and T. B. Paiva, "Effect of cholecalciferol treatment on the relaxant responses of spontaneously hypertensive rat arteries to acetylcholine," Hypertension, vol. 34, no. 4, Part 2, pp. 897-901, 1999.

[50] K. L. Jablonski, M. Chonchol, G. L. Pierce, A. E. Walker, and D. R. Seals, "25-Hydroxyvitamin D deficiency is associated with inflammation-linked vascular endothelial dysfunction in middle-aged and older adults," Hypertension, vol. 57, no. 1, pp. 63-69, 2011.

[51] P. Ranganathan, S. Khalatbari, S. Yalavarthi, W. Marder, R. Brook, and M. J. Kaplan, "Vitamin D deficiency, interleukin 17 , and vascular function in rheumatoid arthritis," The Journal of Rheumatology, vol. 40, no. 9, pp. 1529-1534, 2013.

[52] P. H. Dessein and B. I. Joffe, "Insulin resistance and impaired beta cell function in rheumatoid arthritis," Arthritis \& Rheumatism, vol. 54, no. 9, pp. 2765-2775, 2006.

[53] G. La Montagna, F. Cacciapuoti, R. Buono et al., "Insulin resistance is an independent risk factor for atherosclerosis in rheumatoid arthritis," Diabetes \& Vascular Disease Research, vol. 4, no. 2, pp. 130-135, 2007.

[54] L. de Groot, N. A. Jager, J. Westra et al., "Does reduction of disease activity improve early markers of cardiovascular disease in newly diagnosed rheumatoid arthritis patients?," Rheumatology, vol. 54, no. 7, pp. 1257-1261, 2015. 


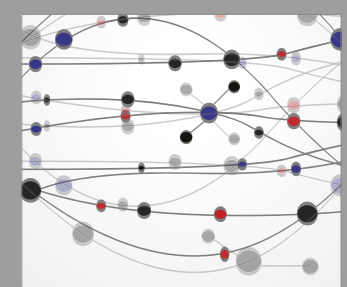

The Scientific World Journal
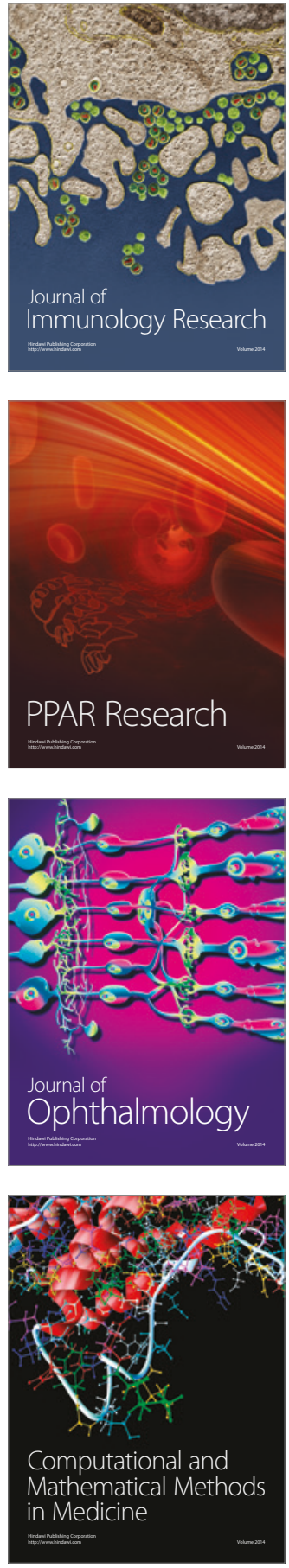

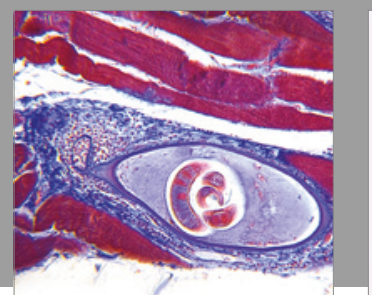

Gastroenterology Research and Practice
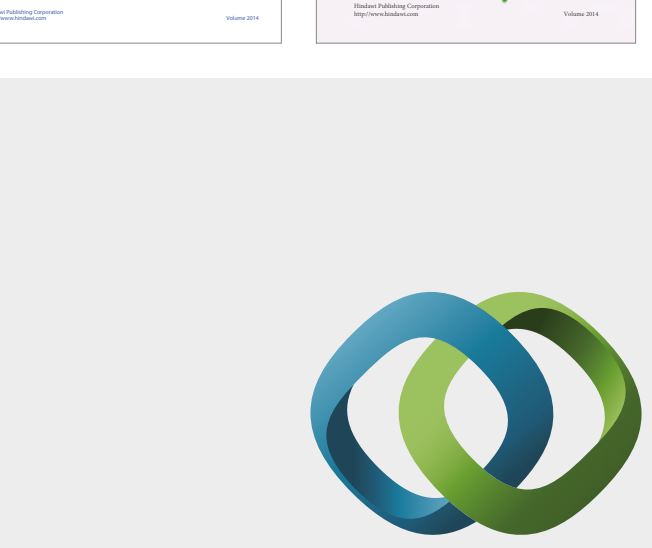

\section{Hindawi}

Submit your manuscripts at

https://www.hindawi.com
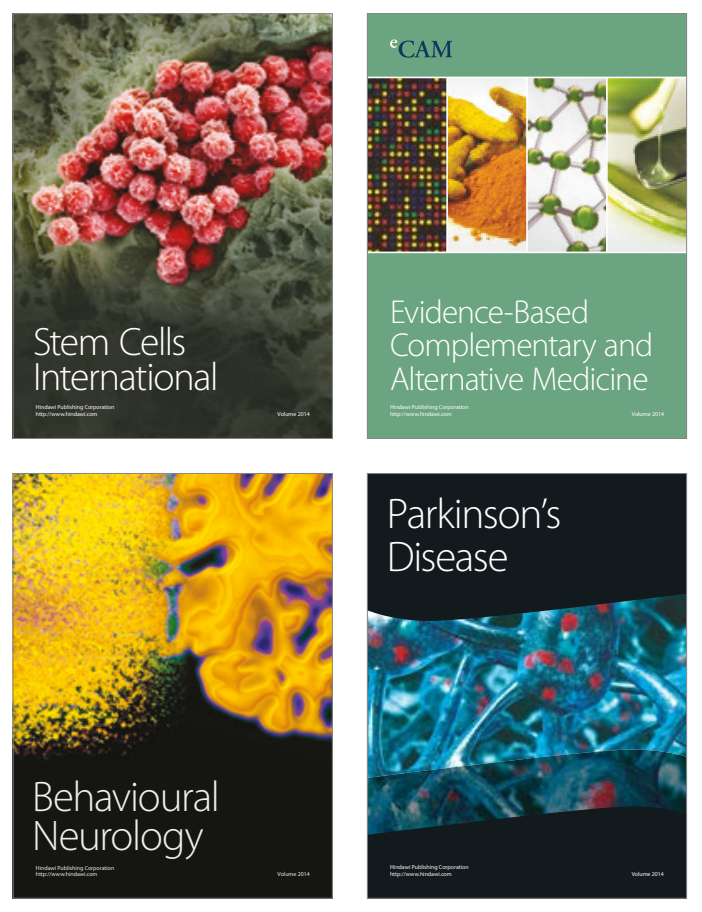
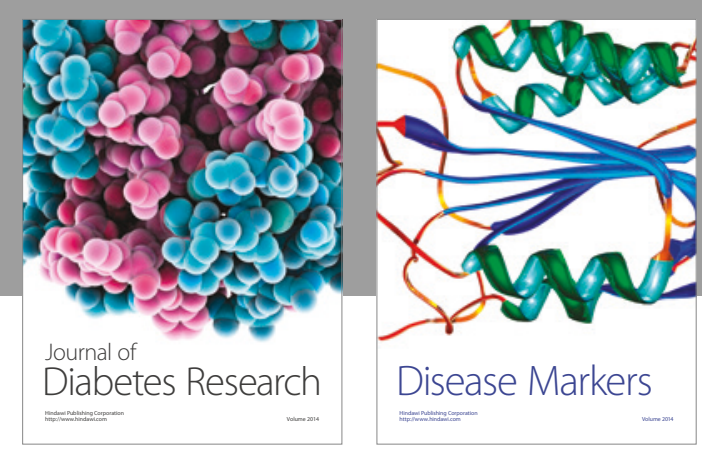

Disease Markers
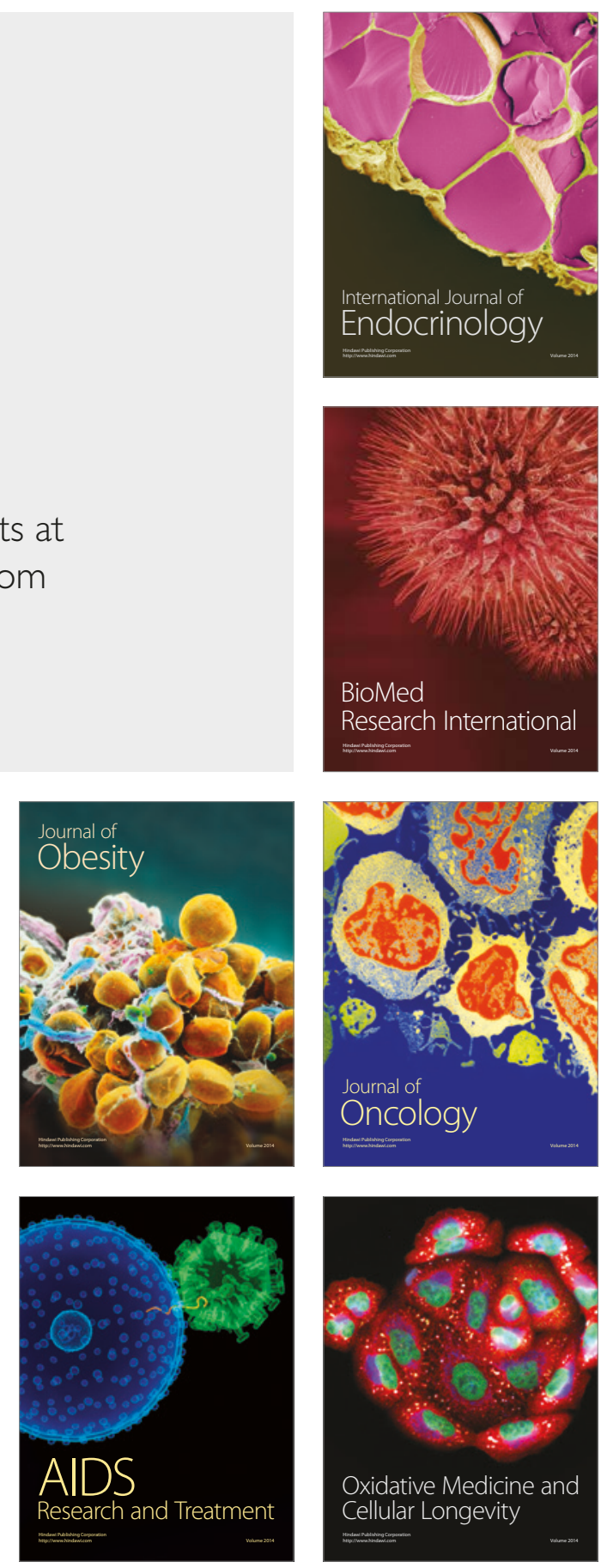